\title{
Large Tumor Size is an Indicator for the Timely Administration of Adjuvant Radiotherapy in Luminal Breast Cancer with Positive Lymph Node
}

This article was published in the following Dove Press journal: Cancer Management and Research

\author{
Kai-Yun You ${ }^{1-3, *}$ \\ Wei-Liang Zou ${ }^{3, *}$ \\ Lin Ding ${ }^{3, *}$ \\ Zhuo-Fei Bi (D) $1-3$ \\ He-Rui Yao ${ }^{1,2,4,5}$ \\ 'Guangdong Provincial Key Laboratory of \\ Malignant Tumor Epigenetics and Gene \\ Regulation, Medical Research Center, Sun \\ Yat-Sen Memorial Hospital, Sun Yat-Sen \\ University, Guangzhou, People's Republic \\ of China; ${ }^{2}$ RNA Biomedical Institute, Sun \\ Yat-Sen Memorial Hospital, Sun Yat-Sen \\ University, Guangzhou, People's Republic \\ of China; ${ }^{3}$ Department of Radiation \\ Oncology, Sun Yat-Sen Memorial \\ Hospital, Sun Yat-Sen University, \\ Guangzhou, People's Republic of China; \\ ${ }^{4}$ Department of Oncology, Sun Yat-Sen \\ Memorial Hospital, Sun Yat-Sen \\ University, Guangzhou, People's Republic \\ of China; ${ }^{5}$ Breast Tumor Center, Sun Yat- \\ Sen Memorial Hospital, Sun Yat-Sen \\ University, Guangzhou, People's Republic \\ of China
}

*These authors contributed equally to this work
Correspondence: He-Rui Yao;

Zhuo-Fei Bi

$\mathrm{Tel} / \mathrm{Fax}+86-20-81332533$

Email yaoherui@mail.sysu.edu.cn;

bizhuof@mail3.sysu.edu.cn
Purpose: The optimum timing of adjuvant radiotherapy for breast cancer patients who had undergone surgery remains unclear. The present study aimed to identify the clinical factors which could assist the selecting of time interval (TI) between surgery and adjuvant radiotherapy in luminal breast cancer with lymph node metastasis.

Patients and Methods: This retrospective study included 1054 luminal breast cancer patients with lymph node metastasis, diagnosed between May 2004 and December 2014, and treated with surgery followed by adjuvant therapy. Overall survival (OS) and diseasefree survival (DFS) were compared between patients in the short and long TI groups. Multivariate analysis was performed to examine clinical factors associated with DFS. Subgroups analysis was further performed based on the significant predictors of DFS to explore the association of TI and tumor prognosis.

Results: For the whole group of patients, there was no difference in OS and DFS between patients with long and short TI. Multivariate analysis showed that age, N stage and tumor size were significant predictors of DFS. Subgroup analysis demonstrated that neither age nor $\mathrm{N}$ stage were informative in TI selection; in contrast, in patients with large tumors, a short TI was associated with better DFS than a long TI. In patients with small tumors, there was no significant association between TI and tumor prognosis. In the multivariable analysis, TI was independent predictor of DFS and local recurrence-free survival in patients with large tumors.

Conclusion: Large tumor size is an indicator for the timely administration of adjuvant radiotherapy in luminal breast cancer with positive lymph node.

Keywords: breast cancer, radiotherapy, time interval, tumor size, surgery

\section{Introduction}

Radiotherapy is an important part of combined modality treatment in patients with breast cancer. A number of randomized clinical trials have shown that adjuvant radiotherapy can decrease the risk of local recurrence and improve survival in breast cancer patients. ${ }^{1-3}$ However, the timing of radiotherapy in patients who have completed surgery remains unclear. In fact, the optimal time interval (TI) between surgery and radiotherapy is still under investigation. ${ }^{4}$

Some previous studies have showed that a long TI between surgery and adjuvant radiotherapy increased the risk of local recurrence. ${ }^{5-9}$ Meanwhile, other studies reported that the TI did not affect tumor prognosis. ${ }^{10-16}$ These inconsistencies are likely accounted for by methodological discrepancies between studies, in 
particular, eligibility criteria. Some patients require adjuvant chemotherapy, leading to a delay in radiotherapy, which tends to be administered after chemotherapy. ${ }^{17}$ Combining these populations in a single study may introduce high heterogeneity, affecting the reliability of study results. A suitable approach to investigating the effects of TI on patient prognosis is to improve the homogeneity of study samples.

Previous studies have shown that $\mathrm{N}$ status is associated with breast cancer outcomes; it was also used as an indicator for the administration of adjuvant radiotherapy. ${ }^{18-20}$ In the present study, we aimed to include luminal breast cancer patients with positive lymph nodes and to investigate the role of TI in predicting the survival in these patients.

\section{Patients and Methods}

\section{Ethics Statement}

We got research permission from Institutional Review Board of Sun Yat-Sen Memorial Hospital. Since the design of current study was retrospective, the written consent associated with the present study was not required in our hospital. Besides, during the research, we have protected the patients' confidential information from disclosure. This study was conducted in accordance with the Declaration of Helsinki.

\section{Patients}

Patients' clinical information was extracted from the hospital database for the period between May 2004 and December 2014. Patients were eligible for the present study if they had a pathologically confirmed diagnosis of invasive luminal (A or B) breast cancer, were treated with surgery followed by adjuvant therapy, and had pathologically confirmed lymph node metastasis. Patients with HER2 over-expression or triple negative, those who received neoadjuvant chemotherapy, and those whose first diagnosis was of metastatic disease were excluded from the present study. Data from a total of 1054 patients were included in the present study.

\section{Treatment}

All included patients underwent surgery. Breast-conserving surgery was performed in 407 cases; the remaining 647 patients underwent mastectomy. None of the patients had a positive surgical margin in their final pathology report. Positive lymph nodes were confirmed in all included patients. After surgery, patients received postoperative chemotherapy, selected based on the NCCN guidelines and attending physicians' experience and typically administered over 4-6 months. After the chemotherapy was completed, adjuvant radiotherapy was initiated using 6- or 10-MV photons. In patients who underwent breast-conserving surgery, the whole breast was irradiated with a dose of $50 \mathrm{~Gy} / 25 \mathrm{~F}$, followed by a boost of 10-16Gy to the tumor bed. Meanwhile, in patients who received mastectomy, the chest wall was the target of radiation delivered at a dose of $50 \mathrm{~Gy} / 25 \mathrm{~F}$. In addition, the lymphatic drainage area was also irradiated according to the individual's condition of lymph node metastasis. In details, in patients with more than 4 positive axillary nodes, the lymphatic drainage areas including infraclavicular region, supraclavicular area, internal mammary nodes, and the axillary bed at risk should be irradiated. In patients with 1-3 positive axillary nodes, the lymph node regions such as infraclavicular and supraclavicular areas, axillary bed at risk were usually the target of radiotherapy. Besides, when patients with 1-3 positive axillary nodes also had other adverse features such as young age, large tumor, and medial quadrant tumor, the radiation field also included internal mammary area. The common prescription dose for lymphatic drainage area was $50 \mathrm{~Gy} / 25 \mathrm{f}$.

The median TI between surgery and adjuvant radiotherapy was 6.4 months (range, $4.5-10.8$ months). Patients were divided into two groups based on the cut-off value of 6.4 months. ${ }^{10}$ "Short" and "long" TI groups were the groups with a TI of $\leq 6.4$ and of $>6.4$ months, respectively.

\section{Follow-Up Evaluation}

During the first 2 years after treatment, patients were followed up every 3-4 months. They were evaluated every 6 months in the following 3 years and annually thereafter. Each evaluation involved blood tests, CA153 assessment, a general physical examination and ultrasonography scanning. Computed tomography scanning and mammography were performed once per year or to aid diagnosis or confirm recurrence, as required. In the present study, local recurrence free-survival (LRFS) was calculated from the time of diagnosis to the observation of any signs of recurrence in the ipsilateral breast, chest wall, or regional lymphatic drainage area. Similarly, distant metastasisfree survival (DMFS) was defined as the time from diagnosis to the development of distant metastasis.

\section{Statistical Analysis}

We used SPSS software (version 19.0) for all statistical analyses. Between-group comparisons of categorical and continuous variables were performed, as suitable, using the chi-square test or Fisher's exact test, and the Student's $t$-test or the Mann-Whitney $U$-test, respectively. Multivariate 
analyses were performed using the cox proportional hazards regression to identify clinical factors significantly associated with DFS. We have put all the possible clinical factors in the cox proportional hazards model by using a forward conditional selection of variables. Survival analysis was performed by using the Kaplan-Meier method with Log rank test. P-values of $<0.05$ were considered indicative of a statistically significant finding.

\section{Results}

\section{Clinical Baseline Characteristics for All the Patients}

Most (95.4\%) patients in both the short and long TI groups had the histologic type of invasive ductal carcinoma, with few patients $(4.6 \%)$ presenting with other histologic type, for example, invasive papillary carcinoma, invasive lobular carcinoma, or mucinous adenocarcinoma. Patients in the short TI group were more likely to have a positive PR status than were those in the long TI group $(96.6 \%$ vs $88.7 \%, \mathrm{P}<0.001)$. Moreover, the patients in the short TI group had a lower proportion of lymphovascular invasion (LVI) than did those in the long TI group ( $15.3 \%$ vs $22.7 \%, \mathrm{P}=0.002)$. Other clinical factors including age, tumor size, $\mathrm{N}$ stage, ER status, HER2 status, molecular types, and follow-up were balanced between the two groups (Table 1).

\section{Survival Analysis for the Whole Group}

During the follow-up period, there were 185 deaths and 263 cases of recurrence. Among the latter, 23 and 175 cases developed local failure and distant metastasis, respectively. Sixtyfive patients experienced both local and distant recurrence. The 10-year OS rates for the short and long TI groups were $74.51 \%$ and $78.18 \%$, respectively. No significant difference was found in OS between the two groups $(\mathrm{P}=0.903)$ (Figure 1). The 10year DFS rates were also comparable between patients with short and long TI ( $71.65 \%$ vs $67.07 \%$, respectively, $\mathrm{P}=0.163)$ (Figure 2).

\section{Clinical Predictors of DFS for the Whole Group}

Univariate analysis revealed that age, $\mathrm{N}$ stage and tumor size were associated with DFS (Table 2). In contrast, tumor grade, LVI, TI, and molecular type were not associated with DFS. Multivariable analysis further confirmed that age, $\mathrm{N}$ stage and tumor size were significant predictors of DFS. Specifically, patients aged $\leq 40$ years achieved shorter DFS than did those aged $>40$ years. Patients with disease stage N2-3 had a 2.42-
Table I Baseline Characteristics of the Patients Included

\begin{tabular}{|c|c|c|c|}
\hline Variables & $\begin{array}{l}\text { Short Time } \\
\text { Interval }(\mathrm{N}=557)\end{array}$ & $\begin{array}{l}\text { Long Time } \\
\text { Interval }(\mathrm{N}=497)\end{array}$ & $P$ value \\
\hline $\begin{array}{l}\text { Age, year } \\
\begin{array}{l}\leq 40 \\
>40\end{array}\end{array}$ & $\begin{array}{l}115 \\
442\end{array}$ & $\begin{array}{l}110 \\
387\end{array}$ & 0.557 \\
\hline $\begin{array}{l}\text { Histologic type } \\
\text { Invasive ductal } \\
\text { carcinoma } \\
\text { Other types }{ }^{\#}\end{array}$ & $\begin{array}{l}523 \\
34\end{array}$ & $\begin{array}{l}483 \\
14\end{array}$ & 0.011 \\
\hline $\begin{array}{l}\text { Tumor size, cm } \\
\leq 2.0 \\
>2.0\end{array}$ & $\begin{array}{l}248 \\
309\end{array}$ & $\begin{array}{l}233 \\
264\end{array}$ & 0.443 \\
\hline $\begin{array}{l}\mathrm{N} \text { stage } \\
\mathrm{NI} \\
\mathrm{N} 2-3\end{array}$ & $\begin{array}{l}325 \\
232\end{array}$ & $\begin{array}{l}286 \\
211\end{array}$ & 0.792 \\
\hline $\begin{array}{l}\text { ER status } \\
\text { Positive } \\
\text { Negative }\end{array}$ & $\begin{array}{l}513 \\
44\end{array}$ & $\begin{array}{l}461 \\
36\end{array}$ & 0.688 \\
\hline $\begin{array}{l}\text { PR status } \\
\text { Positive } \\
\text { Negative }\end{array}$ & $\begin{array}{l}538 \\
19\end{array}$ & $\begin{array}{l}441 \\
56\end{array}$ & $<0.001$ \\
\hline $\begin{array}{l}\text { HER } 2 \text { status } \\
\text { Positive } \\
\text { Negative }\end{array}$ & $\begin{array}{l}106 \\
451\end{array}$ & $\begin{array}{l}114 \\
383\end{array}$ & 0.119 \\
\hline $\begin{array}{c}\text { Molecular type } \\
\text { Luminal A } \\
\text { Luminal B }\end{array}$ & $\begin{array}{l}397 \\
160\end{array}$ & $\begin{array}{l}329 \\
168\end{array}$ & 0.076 \\
\hline $\begin{array}{l}\text { LVI } \\
\text { Yes } \\
\text { No }\end{array}$ & $\begin{array}{l}85 \\
472\end{array}$ & $\begin{array}{l}113 \\
384\end{array}$ & 0.002 \\
\hline $\begin{array}{l}\text { Follow-up, months } \\
\text { Median }\end{array}$ & 75.3 & 73.2 & 0.066 \\
\hline
\end{tabular}

Note: ${ }^{\#}$ Other types included: Invasive papillary carcinoma, invasive lobular carcinoma and mucinous adenocarcinoma.

Abbreviation: LVI, lymphovascular invasion.

fold higher risk of recurrence that did those with disease stage N1. Large tumors were associated with poorer survival than that associated with small tumors.

\section{Subgroup Analysis Based on Factor of Age}

Among patients aged $\leq 40$ years, there were 74 cases of recurrence, including 11, 48, and 15 cases of local recurrence, distant metastasis, and both local and distant failure, respectively. The 10-year OS and DFS were similar between the short and long TI groups $(\mathrm{P}>0.05)$ (Table 3$)$. 


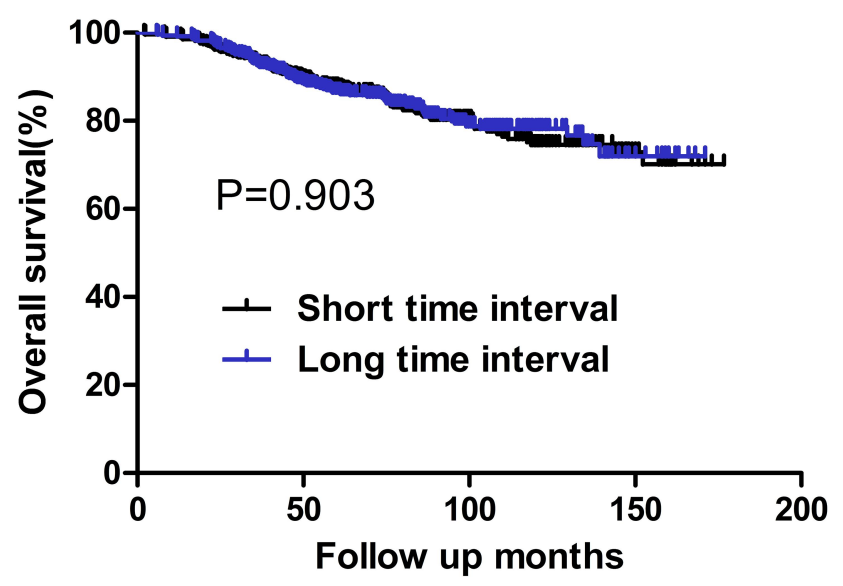

Figure I OS for the whole group stratified by time interval. No significant difference was found in OS between patients with short and long time intervals $(\mathrm{P}=0.903)$.

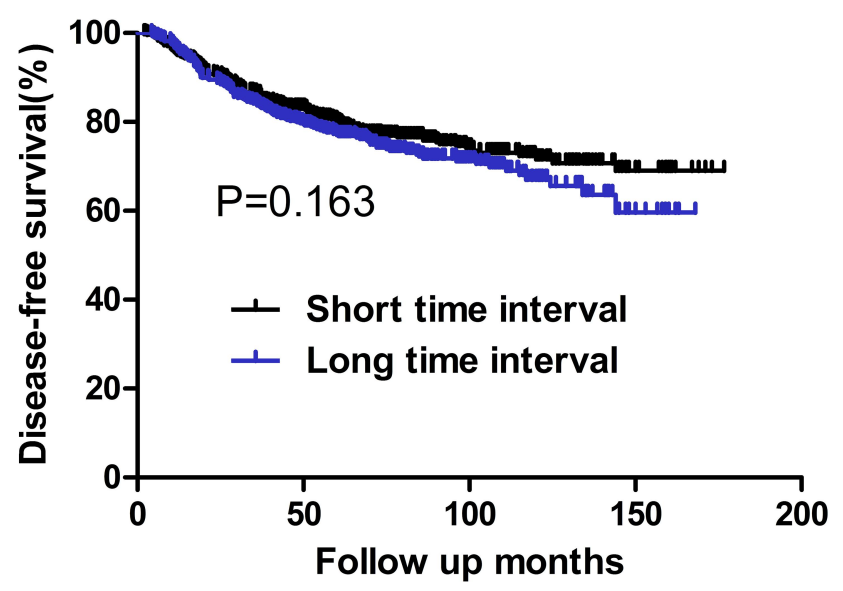

Figure 2 DFS for the whole group stratified by time interval. No significant difference was found in DFS between patients with short and long time intervals $(P=0.163)$.

Among patients aged $>40$ years, there were 189 cases of recurrence. Among them, 12, 127, and 50 cases involved local recurrence, distant metastasis, and both local and distant failures, respectively. The 10-year OS and DFS rates in the short and long TI groups were $77.4 \%$ and $74.7 \%$, and $78.2 \%$ and $70.4 \%$, respectively, without any significant difference (Table 4).

\section{Subgroup Analysis Based on Factor of $\mathrm{N}$ Stage}

Among patients with N1 stage, the 10-year DFS rates for the patients with short and long TI were $78.9 \%$ and $75.9 \%$, respectively, without any significant difference $(\mathrm{P}=0.124)$.
Table 2 Univariate and Multivariate Analyses of DFS

\begin{tabular}{|c|c|c|c|c|}
\hline \multirow[t]{2}{*}{ Variables } & \multicolumn{2}{|c|}{ Univariate Analysis } & \multicolumn{2}{|c|}{ Multivariate Analysis } \\
\hline & HR $(95 \% \mathrm{Cl})$ & $P$ value & HR $(95 \% \mathrm{Cl})$ & $P$ value \\
\hline \multicolumn{5}{|l|}{ Tumor size, cm } \\
\hline$\leq 2.0$ vs $>2.0$ & $\begin{array}{l}0.646 \\
(0.504-0.828)\end{array}$ & 0.001 & $\begin{array}{l}0.718 \\
(0.558-0.924)\end{array}$ & 0.010 \\
\hline \multicolumn{5}{|l|}{ Tumor grade } \\
\hline I-II vs III & $\begin{array}{l}0.935 \\
(0.734-1.191)\end{array}$ & 0.588 & & \\
\hline \multicolumn{5}{|l|}{ LVI } \\
\hline Yes vs no & $\begin{array}{l}0.863 \\
(0.6 \mid 4-1.215)\end{array}$ & 0.400 & & \\
\hline \multicolumn{5}{|l|}{ Molecular type } \\
\hline $\begin{array}{l}\text { Luminal A vs } \\
\text { luminal } B\end{array}$ & $\begin{array}{l}0.786 \\
(0.611-1.011)\end{array}$ & 0.061 & & \\
\hline \multicolumn{5}{|l|}{ Age } \\
\hline$\leq 40$ vs $>40$ & $\begin{array}{l}1.527 \\
(1.167-1.998)\end{array}$ & 0.002 & $\begin{array}{l}1.656 \\
(1.265-2.168)\end{array}$ & $<0.001$ \\
\hline \multicolumn{5}{|l|}{ Time interval } \\
\hline Short vs long & $\begin{array}{l}0.842 \\
(0.661-1.072)\end{array}$ & 0.163 & & \\
\hline \multicolumn{5}{|l|}{$\mathrm{N}$ stage } \\
\hline $\mathrm{NI}$ vs N2-3 & $\begin{array}{l}0.403 \\
(0.314-0.516)\end{array}$ & $<0.001$ & $\begin{array}{l}0.413 \\
(0.321-0.531)\end{array}$ & $<0.001$ \\
\hline
\end{tabular}

Abbreviations: $\mathrm{Cl}$, confidence interval; HR, hazard ratio; LVI, lymphovascular invasion.

Table 3 Survival Analysis for Subgroup of Patients with Age $\leq 40$

\begin{tabular}{|l|c|c|c|c|c|}
\hline \multirow{2}{*}{ Group } & \multicolumn{2}{|c|}{$\begin{array}{c}\text { Short Time } \\
\text { Interval (n=I 15) }\end{array}$} & \multicolumn{2}{|c|}{$\begin{array}{c}\text { Long Time } \\
\text { Interval }(\mathbf{n}=11 \text { 10) }\end{array}$} & \multirow{2}{*}{ P value } \\
\cline { 2 - 5 } & $\mathbf{5 - Y e a r}$ & I0-Year & 5-Year & I0-Year & \\
\hline OS & $83.8 \%$ & $62.7 \%$ & $85.2 \%$ & $78.1 \%$ & $0.168^{*}$ \\
DFS & $75.7 \%$ & $59.4 \%$ & $72.9 \%$ & $57.1 \%$ & $0.715^{*}$ \\
\hline
\end{tabular}

Note: *Calculated by Kaplan-Meier method.

Abbreviations: OS, overall survival; DFS, disease-free survival.

Table 4 Survival Analysis for Subgroup of Patients with Age $>40$

\begin{tabular}{|l|c|c|c|c|c|}
\hline \multirow{2}{*}{ Group } & \multicolumn{2}{|c|}{$\begin{array}{c}\text { Short Time } \\
\text { Interval (n=442) }\end{array}$} & \multicolumn{2}{|c|}{$\begin{array}{c}\text { Long Time } \\
\text { Interval (n=387) }\end{array}$} & \multirow{2}{*}{ P value } \\
\cline { 2 - 5 } & 5-Year & I0-Year & 5-Year & I0-Year & \\
\hline OS & $88.6 \%$ & $77.4 \%$ & $86.8 \%$ & $78.2 \%$ & $0.568 *$ \\
DFS & $81.5 \%$ & $74.7 \%$ & $78.3 \%$ & $70.4 \%$ & $0.202 *$ \\
\hline
\end{tabular}

Note: *Calculated by Kaplan-Meier method.

Abbreviations: OS, overall survival; DFS, disease-free survival. 
Table 5 Survival Analysis for Subgroup of Patients with NI

\begin{tabular}{|l|c|c|c|c|c|}
\hline \multirow{2}{*}{ Group } & \multicolumn{2}{|c|}{$\begin{array}{c}\text { Short Time } \\
\text { Interval (n=325) }\end{array}$} & \multicolumn{2}{|c|}{$\begin{array}{c}\text { Long Time } \\
\text { Interval (n=286) }\end{array}$} & \multirow{2}{*}{ value } \\
\cline { 2 - 5 } & 5-Year & 10-Year & 5-Year & 10-Year & \\
\hline OS & $93.6 \%$ & $83.7 \%$ & $90.2 \%$ & $83.2 \%$ & $0.429 *$ \\
DFS & $89.7 \%$ & $78.9 \%$ & $84.5 \%$ & $75.9 \%$ & $0.124 *$ \\
\hline
\end{tabular}

Note: *Calculated by Kaplan-Meier method.

Abbreviations: OS, overall survival; DFS, disease-free survival.

Table 6 Survival Analysis for Subgroup of Patients with N2-3

\begin{tabular}{|l|c|c|c|c|c|}
\hline \multirow{2}{*}{ Group } & \multicolumn{2}{|c|}{$\begin{array}{c}\text { Short Time } \\
\text { Interval (n=232) }\end{array}$} & \multicolumn{2}{|c|}{$\begin{array}{c}\text { Long Time } \\
\text { Interval (n=21 I) }\end{array}$} & \multirow{2}{*}{ P value } \\
\cline { 2 - 5 } & 5-Year & 10-Year & 5-Year & 10-Year & \\
\hline OS & $79.5 \%$ & $62.5 \%$ & $81.3 \%$ & $71.5 \%$ & $0.405^{*}$ \\
DFS & $67.4 \%$ & $61.0 \%$ & $67.2 \%$ & $56.2 \%$ & $0.606 *$ \\
\hline
\end{tabular}

Note: *Calculated by Kaplan-Meier method.

Abbreviations: OS, overall survival; DFS, disease-free survival.

Similarly, there was also no difference between the two groups in 10 -year OS rates $(83.7 \%$ vs $83.2 \%, \mathrm{P}=0.429)$ (Table 5).

Among patients with N2-3 stage, there were 162 cases of recurrence. There was also no difference in 10-year DFS or OS rates between the short and long TI groups (61.0\% vs $56.2 \%, \mathrm{P}=0.606 ; 62.5 \%$ vs $71.5 \%, \mathrm{P}=0.405$, respectively) (Table 6).

\section{Subgroup Analysis Based on Factor of Tumor Size}

Among patients with the tumor size of $\leq 2.0 \mathrm{~cm}$, there were 101 and 67 cases of recurrence and death during the follow-up period, respectively. There was no difference in 10-year DFS or OS rates between the short and long TI groups $(72.2 \%$ vs $73.4 \%, \mathrm{p}=0.711$; and $79.2 \%$ vs $82.7 \%, \mathrm{P}=0.932$, respectively) (Table 7). Among patients with a tumor size of $>2.0 \mathrm{~cm}$, the 10-year DFS rates of the short and long TI groups were $71.5 \%$ and $61.7 \%$,

Table 7 Survival Analysis for Subgroup of Patients with the Tumor Size of $\leq 2.0 \mathrm{~cm}$

\begin{tabular}{|l|c|c|c|c|c|}
\hline \multirow{2}{*}{ Group } & \multicolumn{2}{|c|}{$\begin{array}{c}\text { Short Time } \\
\text { Interval (n=248) }\end{array}$} & \multicolumn{2}{|c|}{$\begin{array}{c}\text { Long Time } \\
\text { Interval (n=233) }\end{array}$} & \multirow{2}{*}{ P value } \\
\cline { 2 - 5 } & 5-Year & 10-Year & 5-Year & 10-Year & \\
\hline OS & $91.1 \%$ & $79.2 \%$ & $90.8 \%$ & $82.7 \%$ & $0.932^{*}$ \\
DFS & $84.2 \%$ & $72.2 \%$ & $86.2 \%$ & $73.4 \%$ & $0.711^{*}$ \\
\hline
\end{tabular}

Note: *Calculated by Kaplan-Meier method.

Abbreviations: OS, overall survival; DFS, disease-free survival.

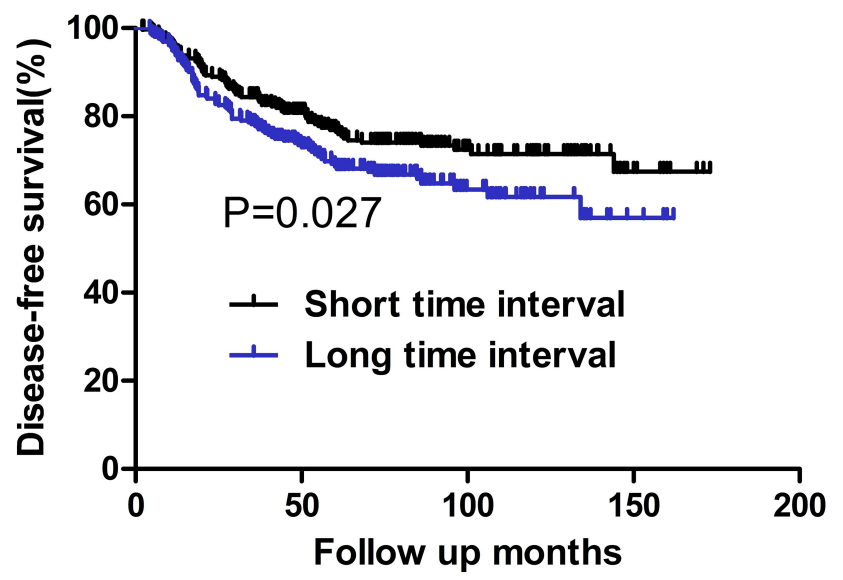

Figure 3 DFS for patients with the tumor size of $>2.0 \mathrm{~cm}$ stratified by time interval. Patients with short time interval had a significantly higher DFS than those with long time interval $(P=0.027)$.

respectively. The long TI group had a significantly lower DFS rate than did the short TI group ( $\mathrm{P}=0.027)$ (Figure 3); however, the OS was similar between the two groups (70.8\% vs $73.8 \%, \quad \mathrm{P}=0.917$ ) (Table 8) (Figure 4). Moreover, we tended to explore how TI affected the DFS by analyzing the recurrence pattern. The results showed that the local recurrence rate was higher in patients with a long TI than in those with a short TI. However, there was no between-group difference in the rate of distant metastasis (Table 9). Overall, these findings suggested that, for the patients with the tumor size $>2.0 \mathrm{~cm}$, a long TI would resulted in an impaired local control, thus leading to decreased DFS.

\section{Clinical Predictors for DFS, LRFS, and DMFS in Patients with the Tumor Size of $>2.0 \mathrm{~cm}$}

In multivariate analysis, TI, age, and $\mathrm{N}$ stage were independent predictors of DFS in breast cancer patients with the tumor size of $>2.0 \mathrm{~cm}$. The TI was particularly strongly associated with local recurrence free-survival

Table 8 Survival Analysis for Subgroup of Patients with the Tumor Size of $>2.0 \mathrm{~cm}$

\begin{tabular}{|l|c|c|c|c|c|}
\hline \multirow{2}{*}{ Group } & \multicolumn{2}{|c|}{$\begin{array}{c}\text { Short Time } \\
\text { Interval (n=309) }\end{array}$} & \multicolumn{2}{|c|}{$\begin{array}{c}\text { Long Time } \\
\text { Interval (n=264) }\end{array}$} & \multirow{2}{*}{ P value } \\
\cline { 2 - 5 } & $\mathbf{5 - Y e a r}$ & I0-Year & 5-Year & 10-Year & \\
\hline OS & $84.8 \%$ & $70.8 \%$ & $82.5 \%$ & $73.8 \%$ & $0.915^{*}$ \\
DFS & $77.0 \%$ & $71.5 \%$ & $68.7 \%$ & $61.7 \%$ & $0.027^{*}$ \\
\hline
\end{tabular}

Note: *Calculated by Kaplan-Meier method.

Abbreviations: OS, overall survival; DFS, disease-free survival. 


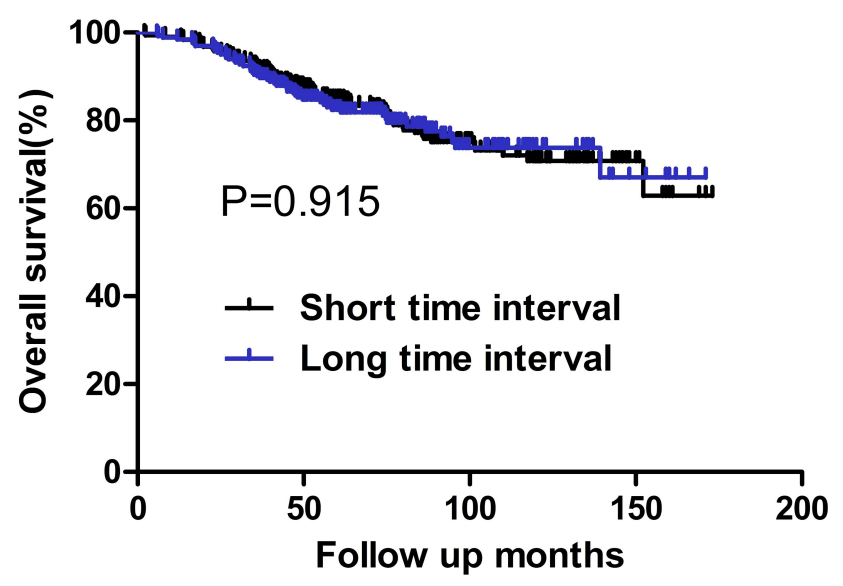

Figure 4 OS for patients with the tumor size of $>2.0 \mathrm{~cm}$ stratified by time interval. No significant difference was found in OS between patients with short and long time intervals $(\mathrm{P}=0.915)$.

but not with distant metastasis-free survival. Besides, $\mathrm{N}$ stage was found to be the unique predictor of distant metastasis-free survival in patients with the tumor size of $>2.0 \mathrm{~cm}$ (Table 10).

\section{Discussion}

The present study has shown that the 10-year DFS and OS rates in the long and short TI groups were similar. In multivariable analysis, tumor size, $\mathrm{N}$ status and age were found to be independent predictors of DFS. Moreover, subgroup analysis revealed that among patients with large tumors, the long TI group had lower DFS rates than did the short TI group; however, a similar relationship was not observed among patients with small tumors. Next, we tried to answer how TI affected the DFS by analyzing the recurrence pattern in patients with large tumors. Results showed that a long TI was associated with a higher rate of local failure and, consequently, poorer DFS than those associated with a short TI. In the multivariate analysis, TI was an independent predictor of DFS and LRFS in patients with a tumor size of $>2.0 \mathrm{~cm}$. Overall, the present findings suggest that tumor size might be

Table 9 Recurrence Patterns for Patients with the Tumor Size of $>2.0 \mathrm{~cm}$

\begin{tabular}{|l|c|c|c|c|c|}
\hline \multirow{2}{*}{ Group } & \multicolumn{2}{|c|}{$\begin{array}{c}\text { Short Time } \\
\text { Interval (n=309) }\end{array}$} & \multicolumn{2}{|c|}{$\begin{array}{c}\text { Long Time } \\
\text { Interval }\end{array}$} & \multirow{2}{*}{ P value } \\
\cline { 2 - 5 } & 5-Year & I0-Year & 5-Year & 10-Year & \\
\hline LR & $6.3 \%$ & $7.7 \%$ & $12.6 \%$ & $13.2 \%$ & $0.018^{*}$ \\
SM & $21.8 \%$ & $26.9 \%$ & $26.7 \%$ & $35.2 \%$ & $0.087^{*}$ \\
\hline
\end{tabular}

Note: *Calculated by Kaplan-Meier method.

Abbreviations: LR, local recurrence; SM, systemic metastases. a useful indicator in deciding the TI between surgery and radiotherapy for luminal breast cancer patients.

The selection of TI between surgery and adjuvant radiotherapy is still an unsolved clinical problem. Previous studies have attempted to define the role of TI in predicting the tumor prognosis; however, their findings were inconsistent. ${ }^{4-17}$ One previous study that included 18050 breast cancer patients treated with surgery and adjuvant radiotherapy, reported that a long TI was associated with the increased likelihood of local recurrence (hazard ratio $=1.19,95 \%$ confidence interval: 1.01 to $1.39, \mathrm{P}=0.033){ }^{6}$ A systematic review of 34 relevant studies with a total of 79,616 breast cancer patients reported that the relative risk of local recurrence per month of delay was 1.08 (95\% confidence interval 1.02-1.14). ${ }^{9}$ The study authors recommend that waiting times for radiotherapy should be kept as short as reasonably achievable. A delay in radiotherapy may allow residual tumor cells present in the surgical bed to develop into the local and distant recurrence over time; moreover, a longer TI between surgery and radiotherapy may offer enough time for the residual tumor cells to grow and develop treatment-resistance trait. ${ }^{21,22}$ However, there were also studies which yielded different findings. A study by Caponio et al, in which 615 breast cancer patients were divided into three groups according to the timing of radiotherapy $(\leq 60,61-120$, and $>120$ days) and followed up for 15 years, reported no relationship between the TI and the risk of local recurrence. ${ }^{11}$ In another study, Barbieri et al included a total of 387 patients with T1-2 breast cancer were treated with breast-conserving surgery and radiotherapy, showing no impact of a delay in radiotherapy on the risk of local relapse. ${ }^{12}$ However, a major limitation of this study was in the selection criteria, which did not consider the differences in TI between patients who did and did not undergo chemotherapy. ${ }^{12}$

Compared to the previous reports, the present study has shown that the tumor size may affect the optimum TI between surgery and adjuvant radiotherapy for luminal breast cancer patients with positive lymph node. We found that, among patients with large tumors, a longer TI was associated with reduced DFS, while it did not affect the outcomes of patients with small tumors. This finding may be due to the fact that a large tumor may invade the adjacent tissue more seriously than a small one, making complete resection challenging. As we know, this is the first study to show that tumor size may be used in decisions regarding the TI between surgery and adjuvant radiotherapy for patients with luminal breast cancer with lymph node metastasis. We suggested a timely radiotherapy should be administered to those patents with large tumors in order to increase the likelihood of achieving good local control. 
Table 10 Multivariate Analyses of DFS, LRFS, and DMFS for Patients with the Tumor Size of $>2.0 \mathrm{~cm}$

\begin{tabular}{|c|c|c|c|c|c|c|}
\hline \multirow[t]{2}{*}{ Variables } & \multicolumn{2}{|l|}{ DFS } & \multicolumn{2}{|l|}{ LRFS } & \multicolumn{2}{|c|}{ DMFS } \\
\hline & HR(95\% Cl) & $P$ value & $\operatorname{HR}(95 \% \mathrm{Cl})$ & $P$ value & HR(95\% Cl) & $P$ value \\
\hline \multicolumn{7}{|l|}{$\mathrm{N}$ stage } \\
\hline $\mathrm{NI}$ vs N2-3 & $0.387(0.277-0.540)$ & $<0.001$ & NA & & $0.379(0.267-0.538)$ & $<0.001$ \\
\hline \multicolumn{7}{|l|}{ Age } \\
\hline$\leq 40$ vs $>40$ & $1.642(1.158-2.329)$ & 0.005 & $2.122(1.174-3.835)$ & 0.013 & NA & \\
\hline \multicolumn{7}{|l|}{ Time interval } \\
\hline Short vs long & $0.73 \mid(0.537-0.996)$ & 0.047 & $0.509(0.290-0.893)$ & 0.019 & NA & \\
\hline
\end{tabular}

Abbreviations: DFS, disease-free survival; LRFS, local recurrence-free survival; DMFS, distant metastasis-free survival; Cl, confidence interval; HR, hazard ratio; NA, not available.

Besides, our study can also help improve the treatment efficacy in a single radiation center. Usually, radiotherapy for breast cancer tends to involve long waiting times due to the lack of adequate equipment, a desire for breast reconstruction, and the poor wound healing. ${ }^{23}$ Based on our finding, long waiting times may be inconsequential for patients with small tumors, thereby creating an opportunity for the treatment of patients with large tumors to be prioritized.

This study had some limitations. First, the retrospective design have undermine its importance when compared with prospective clinical trials. Although we suggested that large tumor size could be an indication for the timely adjuvant radiotherapy, this conclusion requires validation in large randomized clinical trials. In addition, the optimal time interval between surgery and adjuvant radiotherapy for different patient subgroups still requires further investigation.

\section{Conclusion}

In conclusion, tumor size can be a reference in the selection of TI in luminal breast cancer patients with lymph node metastasis. And a timely adjuvant radiotherapy should be given to the patients with large tumors.

\section{Funding}

This study was supported by the National Natural Science Foundation of China (81572596, 81972471, U1601223), the Natural Science Foundation of Guangdong Province (2017A030313828, 2016A030313312), the Guangzhou Science and Technology Major Program (201704020131), the Sun Yat-Sen University Clinical Research 5010 Program (2018007), the Sun Yat-Sen Clinical Research Cultivating
Program (SYS-C-201801), and the grant from Guangdong Science and Technology Department (2017B030314026).

\section{Disclosure}

The authors declare that they have no competing interests.

\section{References}

1. Clarke M, Collins R, Darby S, et al.; Early Breast Cancer Trialists' Collaborative Group (EBCTCG). Effects of radiotherapy and of differences in the extent of surgery for early breast cancer on local recurrence and 15-year survival: an overview of the randomised trials. Lancet. 2005;366(9503):2087-2106.

2. Darby S, McGale P; Early Breast Cancer Trialists' Collaborative Group (EBCTCG), et al. Effect of radiotherapy after breast-conserving surgery on 10-year recurrence and 15-year breast cancer death: meta-analysis of individual patient data for 10,801 women in 17 randomised trials. Lancet. 2011;378 (9804):1707-1716.

3. McGale P, Taylor C; EBCTCG (Early Breast Cancer Trialists' Collaborative Group), et al. Effect of radiotherapy after mastectomy and axillary surgery on 10-year recurrence and 20 -year breast cancer mortality: meta-analysis of individual patient data for 8135 women in 22 randomised trials. Lancet. 2014;383(9935):2127-2135. doi:10.1016/S0140-6736(14)60488-8.

4. Tsoutsou PG, Koukourakis MI, Azria D, Belkacémi Y. Optimal timing for adjuvant radiation therapy in breast cancer: a comprehensive review and perspectives. Crit Rev Oncol Hematol. 2009;71 (2):102-116. doi:10.1016/j.critrevonc.2008.09.002

5. Chen Z, King W, Pearcey R, Kerba M, Mackillop WJ. The relationship between waiting time for radiotherapy and clinical outcomes: a systematic review of the literature. Radiother Oncol. 2008;87 (1):3-16. doi:10.1016/j.radonc.2007.11.016

6. Punglia RS, Saito AM, Neville BA, Earle CC, Weeks JC. Impact of interval from breast conserving surgery to radiotherapy on local recurrence in older women with breast cancer: retrospective cohort analysis. BMJ. 2010;340:c845. doi:10.1136/bmj.c845

7. Vujovic O, Cherian A, Yu E, Dar AR, Stitt L, Perera F. The effect of timing of radiotherapy after breast-conserving surgery in patients with positive or close resection margins, young age, and node-negative disease, with long term follow-up. Int J Radiat Oncol Biol Phys. 2006;66(3):687-690. doi:10.1016/j.ijrobp.2006.05.051 
8. Huang J, Barbera L, Brouwers M, Browman G, Mackillop WJ. Does delay in starting treatment affect the outcomes of radiotherapy? A systematic review. $J$ Clin Oncol. 2003;21(3):555-563. doi:10.1200/JCO.2003.04.171

9. Gupta S, King WD, Korzeniowski M, Wallace DL, Mackillop WJ. The effect of waiting times for postoperative radiotherapy on outcomes for women receiving partial mastectomy for breast cancer: a systematic review and meta-analysis. Clin Oncol ( $R$ Coll Radiol). 2016;28(12):739-749. doi:10.1016/j.clon.2016.07.010

10. Cèfaro GA, Genovesi D, Marchese R, et al. The effect of delaying adjuvant radiation treatment after conservative surgery for early breast cancer. Breast J. 2007;13:575-580. doi:10.1111/j.15244741.2007.00511.x

11. Caponio R, Ciliberti MP, Graziano G, et al. Waiting time for radiation therapy after breast-conserving surgery in early breast cancer: a retrospective analysis of local relapse and distant metastases in 615 patients. Eur J Med Res. 2016;21(1):32. doi:10.1186/s40001016-0226-9

12. Barbieri V, Sanpaolo P, Genovesi D. Interval between breast-conserving surgery and start of radiation therapy in early-stage breast cancer is not predictive of local recurrence: a single-institution experience. Clin Breast Cancer. 2011;11(2):114120. doi:10.1016/j.clbc.2011.03.004

13. van Maaren MC, Bretveld RW, Jobsen JJ, et al. The influence of timing of radiation therapy following breast-conserving surgery on 10-year disease-free survival. Br J Cancer. 2017;117(2):179-188. doi: $10.1038 /$ bjc. 2017.159

14. Corradini S, Niemoeller OM, Niyazi M, et al. Timing of radiotherapy following breast-conserving surgery: outcome of 1393 patients at a single institution. Strahlenther Onkol. 2014;190(4):352-357. doi:10.1007/s00066-013-0540-x

15. Karlsson P, Cole BF, Colleoni M, et al. Timing of radiotherapy and outcome in patients receiving adjuvant endocrine therapy. Int J Radiat Oncol Biol Phys. 2011;80(2):398-402. doi:10.1016/j. ijrobp.2010.02.042
16. Karlsson P, Cole BF, Price KN, et al. Timing of radiation therapy and chemotherapy after breast-conserving surgery for node-positive breast cancer: long-term results from international breast cancer study group trials VI and VII. Int $J$ Radiat Oncol Biol Phys. 2016;96(2):273-279. doi:10.1016/j.ijrobp.2016.06.2448

17. Raphael MJ, Saskin R, Singh S. Association between waiting time for radiotherapy after surgery for early-stage breast cancer and survival outcomes in Ontario: a population-based outcomes study. Curr Oncol. 2020;27(2):e216-e221. doi:10.3747/co.27.5629

18. Luini A, Gatti G, Ballardini B, et al. Development of axillary surgery in breast cancer. Ann Oncol. 2005;16(2):259-262. doi:10.1093/ annonc/mdi060

19. Cianfrocca M, Goldstein LJ. Prognostic and predictive factors in early-stage breast cancer. Oncologist. 2004;9(6):606-616. doi:10.1634/theoncologist.9-6-606

20. National Comprehensive Cancer Network. NCCN clinical practice guidelines in oncology_breast cancer; 2019. Available from: http:// www.nccn.org/. Accessed February 02, 2021

21. Mackillop WJ, Bates JH, O'Sullivan B, Withers HR. The effect of delay in treatment on local control by radiotherapy. Int $J$ Radiat Oncol Biol Phys. 1996;34(1):243-250. doi:10.1016/0360-3016(95) 02049-7

22. Veenhof AA, Sietses C, von Blomberg BM, et al. The surgical stress response and postoperative immune function after laparoscopic or conventional total mesorectal excision in rectal cancer: a randomized trial. Int J Colorectal Dis. 2011;26(1):53-59. doi:10.1007/s00384010-1056-9

23. Belkacémi Y, Fourquet A, Cutuli B, et al. Radiotherapy for invasive breast cancer: guidelines for clinical practice from the French expert review board of Nice/Saint-Paul de Vence. Crit Rev Oncol Hematol. 2011;79(2):91-102. doi:10.1016/j.critrevonc.2010.06.002

\section{Publish your work in this journal}

Cancer Management and Research is an international, peer-reviewed open access journal focusing on cancer research and the optimal use of preventative and integrated treatment interventions to achieve improved outcomes, enhanced survival and quality of life for the cancer patient.
The manuscript management system is completely online and includes a very quick and fair peer-review system, which is all easy to use. Visit http://www.dovepress.com/testimonials.php to read real quotes from published authors. 